\title{
Provocações deleuzeanas para as linguagens documentárias ${ }^{1}$
}

\author{
Deleuze's provocations to documentary languages
}

\begin{abstract}
Walter Moreira
Doutor em Ciência da Informação pela Escola de Comunicações e Artes, Universidade de São Paulo - USP Professor Titular do curso de Biblioteconomia das Faculdades Integradas Teresa D'Ávila

E-mail: walter.moreira@gmail.com
\end{abstract}

\begin{abstract}
Resumo
Os sistemas mais tradicionais de representação do conhecimento são baseados em hierarquias, considerando-se seus diversos níveis de rigidez. Os tesauros e, mais recentemente, as ontologias têm trazido mais flexibilidade para a construção de linguagens documentárias. Neste cenário, o artigo convida a algumas reflexões sobre a adequação da lógica da árvore como o modelo de representação do conhecimento e discute a adoção de um novo olhar a partir da proposta do rizoma deleuzeano e suas possíveis implicações para a organização do conhecimento na ciência da informação. Discute as implicações da lógica do decalque nos processos usuais de representação da informação. Considera que a construção de linguagens documentárias modernas não ocorre isoladamente, mas dentro de redes de informação, o que significa que a lógica da árvore não é exatamente o modelo ideal de representação do conhecimento. Discute a possibilidade de adotar o modelo deleuzeana em tais processos.
\end{abstract}

Palavras-chave: Linguagens documentárias; Rizoma; Representação do conhecimento. Organização do conhecimento

\begin{abstract}
The more traditional systems of knowledge representation are based on hierarchies, in its various levels of rigidity. Thesaurus and, more recently, ontologies have brought more flexibility to the construction of documentary languages. In this scenario, the article invites for some reflections on the suitability of the tree's logic as the knowledge representation model and discusses the adoption of a new look from the Deleuzian's rhizome proposal and its possible implications for the organization of knowledge in information science. Discusses the implications of decal logic in usual processes of information representation. Considers that the construction of moderns indexing languages does not occur in isolation, but within information networks, what means that the tree's logic is not exactly the ideal model for knowledge representation. Discusses the possibility of adopting the deleuzean model in such processes.
\end{abstract}

Keywords: Documentary languages; Rhizome; Knowledge representation; Knowledge Organization.

\footnotetext{
${ }^{1}$ Este artigo é parte de pesquisa realizada para tese de doutorado em Ciência da Informação, concluída em 2010, na Escola de Comunicações e Artes da USP, sob orientação da Profa. Dra. Marilda Lopes Ginez de Lara.
}

InCID: R. Ci. Inf. e Doc., Ribeirão Preto, v. 1, n. 2, p. 21-36, jul./dez. 2010. 


\section{Introdução}

As hierarquias formam a base dos sistemas mais tradicionais de representação do conhecimento, mesmo nas classificações filosóficas, origem das classificações bibliográficas, encontram-se sistemas com maior ou menor grau de hierarquização, como se pode verificar, tomando-se como exemplo, na proposta de Cassiodoro que serviu de base para o ensino nas escolas medievais. Em seu sistema, o trivium (as ciências da palavra: gramática, dialética e retórica) e o quadrivium (as ciências das coisas: geometria, aritmética, astronomia e música) formam a base para os chamados estudos superiores (teologia, metafísica, ética e história). As classificações bibliográficas tornar-se-ão menos rígidas do ponto de vista da hierarquização, ainda que não as dispense, principalmente com os estudos de Ranganathan. $\mathrm{Na}$ história dos processos de organização da informação e do conhecimento, os tesauros e, mais recentemente, as ontologias trouxeram mais flexibilidade à construção de informações documentárias.

Não se pretende com este artigo polarizar a questão e apontar questionamentos à corrente que compreende as hierarquias, múltiplas ou não, como condicionantes do que hoje se entende como organização do conhecimento, conforme sua aplicação nas diversas linguagens documentárias, pretende-se, sim, dar voz a outro discurso, provocar outras reflexões. A história das ideias ensina que duas grandes correntes de pensamento quase nunca são similares, pois não pertencem ao mesmo recorte epistemológico da realidade, por esta razão empreende-se este esforço de reflexão.

\section{A lógica da árvore como modelo de representação}

Uma linguagem documentária, como o tesauro, permite representar, para fins documentários, a informação registrada. Para isso é necessário estruturar um sistema conceitual de relações que permita delimitar o universo de interpretação dos signos documentários. Neste sistema os conceitos não existem isoladamente, mas coexistem e condicionam sua compreensão ao tipo de relacionamento que estabelecem com outros conceitos.

Os relacionamentos entre os conceitos, na proposta da terminologia wüsteriana, dividem-se em lógicos (gênero-espécie) e ontológicos (todo-parte). As relações lógicas são 
estabelecidas apenas no plano conceitual, não refletem a experiência concreta. Cita-se, como exemplo, a relação entre mamífero e leão. Já as relações ontológicas são relações indiretas entre conceitos porque resultam das propriedades que possuem os objetos do mundo empírico, como, por exemplo, a relação entre relógio analógico e ponteiro. Trata-se, como se vê, de uma tipologia de raiz binária, na qual todas as outras relações são derivadas das primeiras.

Arnzt e Picht (apud CABRÉ; MOREL; TEBÉ, 1996) redefinem a tipologia de Wüster adotando duas novas superclasses de relações: as relações hierárquicas e as relações nãohierárquicas. As relações hierárquicas englobam as relações lógicas e as relações ontológicas wüsterianas; as relações não-hierárquicas contemplam as relações conceituais regidas por critérios que não incluem as hierarquias, entre as quais se encontram, por exemplo, as relações causais.

A norma ISO 704 (INTERNATIONAL STANDARDIZATION FOR ORGANIZATION, 2000) segue, ao que parece, esta tipologia, agrupando as relações em: hierárquicas (genéricas, partitivas) e associativas. Essa dissociação, ainda dicotômica, rebatese, certamente, nas condições e na qualidade da representação visual que se pode gerar dos relacionamentos conceituais que serão estabelecidos. Se as relações hierárquicas são facilmente demonstráveis por meio de ferramentas gráficas, isso não é tão tranquilo quando se trata das relações associativas, precisamente porque são mais abertas, menos previsíveis e potencialmente mais ricas.

Afora algumas experiências mais ricas em interatividade, como o Visual Thesaurus ${ }^{2}$ (na verdade, um dicionário em interface hiperbólica), que permite criar mapas que representam os significados das palavras e identificam palavras relacionadas, ainda está muito presente o modelo representacional da árvore nas representações visuais dos produtos gerados pela lexicografia ou pela terminologia, apesar de todos os avanços em direção à complexidade verificados nestes campos.

Considerando-se que esta representação não ocorre de modo isolado, mas no interior de redes de informação, não é necessariamente a lógica da árvore o modelo ideal para a representação do conhecimento. Deleuze e Guattari (1995) contrapõem esta linha

\footnotetext{
${ }^{2}$ Disponível em: <http://www.visualthesaurus.com/>. Acesso em: 01 mar. 2010.
} 
arborescente a uma lógica dos múltiplos singulares. Compreender se e como a ciência da informação pode apropriar-se de sua instigante filosofia é o desafio.

\section{Um novo olhar: o rizoma}

Gilles Deleuze (1925-1995) é um dos principais pensadores franceses da contemporaneidade. De modo semelhante ao que acontece quando são propostas idéias inovadoras, quando as estruturas assentadas precisam ser revistas, quando velhos paradigmas - assim como se faz com os tapetes - precisam ser batidos para que sejam limpos, o pensamento legitimamente filosófico de Deleuze instaura novos olhares para o modo como se compreende e, por extensão, como se representa o mundo. Discute-se, portanto, o conceito de rizoma ${ }^{3}$ apresentado pelo autor e suas possíveis implicações na organização do conhecimento enquanto saber/poder/fazer da ciência da informação.

Deleuze caminha, ao longo de sua produção científica, da geração de obras sobre história da filosofia (Nietzsche, Kant, Bergson e Spinoza) e crítica literária (Proust, Zola, Kafka) para a filosofia crítica (Diferença e repetição, Lógica do sentido, O anti-Édipo: capitalismo e esquizofrenia e Mil platôs: capitalismo e esquizofrenia, estes dois últimos com Felix Guattari). O filósofo recebeu pouca atenção crítica na França. Em parte isso é creditado, advertem seus estudiosos (LECHTE, 2002), à sua rejeição sistemática da relação mestrediscípulo, ao fato de não reverenciar os pensadores que o antecederam (com exceção de Nietzsche), como fizeram seus contemporâneos. Para Deleuze, ensina Lechte (2002), um filósofo que pensa, que cria um evento no pensamento, separa-se da história da filosofia e entra no deserto, conforme a compreensão nietzscheana deste termo ${ }^{4}$. A relação que Deleuze estabelece com as obras de Nietzsche, com os textos literários, o cinema, a música popular e a pintura "fizeram-no evoluir para um questionamento não destruidor, mas crítico, até mesmo desconstrutor, de todos os grandes saberes constituídos" (ROUDINESCO, 2007, p. 205).

\footnotetext{
${ }^{3}$ Em botânica, chama-se rizoma a um tipo de caule que algumas plantas verdes possuem, cujo crescimento é horizontal e muitas vezes subterrâneo, podendo também ter porções aéreas. Certos rizomas, como em várias espécies de capim (gramíneas), servem como órgãos de reprodução vegetativa ou assexuada, desenvolvendo raízes e caules aéreos nos seus nós. Em outros casos, o rizoma pode servir como órgão de reserva de energia, na forma de amido, tornando-se tuberoso, mas com uma estrutura diferente de um tubérculo (VIDAL; VIDAL, 2003, p. 102).

4 “[...] Nietzsche encerrara a primeira parte de 'Humano, Demasiado Humano' com uma rapsódia ao peregrino filosófico e sua relação com a noite e com a manhã iminente. No aforismo número 638 ele escreve: É verdade que tal pessoa há de sofrer noites difíceis, em que estará cansado e encontrará fechado o portal da cidade que deveria lhe oferecer descanso. Isso é ruim, porque o deserto chega até o portal e a noite cai como um segundo deserto. [...]" (SAFRANSKI, 2005, p. 200).
}

InCID: R. Ci. Inf. e Doc., Ribeirão Preto, v. 1, n. 2, p. 21-36, jul./dez. 2010. 
A obra de Deleuze é, no mínimo, provocadora. Numa leitura idiossincrática, convida, por meio da crítica que faz ao estruturalismo, à reflexão sobre um dos temas mais relevantes para a ciência da informação: a organização do conhecimento. O conceito de rizoma, desenvolvido pelo autor juntamente com Felix Guattari, e sua já clássica oposição à árvore em especial, interessa de perto a este campo, já que relaciona fortemente a organização com a hierarquização e seus consequentes desdobramentos. A proposta do rizoma é explorada em Mil Platôs, recebendo maior ênfase (um platô inteiro, na verdade) no primeiro volume da obra, o qual será discutido a seguir.

Mil Platôs compartilha com o Anti-Édipo, também de Deleuze em parceria com Guattari, o subtítulo capitalismo e esquizofrenia. Entretanto, ainda que os autores afirmem tratar-se de continuação e final do que fora tratado no Anti-Édipo, suas recepções, dadas as condições contextuais foram distintas.

O Anti-Édipo ainda pertence a 68 (publicado em 1972), surge, portanto, numa "época agitada", oposta, em certo sentido, à "calmaria já absoluta, a indiferença em que o outro surgiu”, em 1980 (DELEUZE; GUATTARI, 1995, p. 7). A data referida, observe-se, é da publicação original; Mil Platôs foi publicado no Brasil apenas 15 anos depois, no ano de 1995, em cinco volumes concluídos em 1997.

No Anti-Édipo, os autores denunciam as “falhas de Édipo, do 'papai-mamãe' na psicanálise, na psiquiatria e até mesmo na antipsiquiatria, na crítica literária e na imagem geral que se faz do pensamento" (DELEUZE; GUATTARI, 1995, p. 7). Como se colocam contra a representação, rejeitam também o que Édipo representa na psicanálise.

Mil Platôs avança, constrói o conceito de multiplicidade, como rejeição e superação dos dualismos um/múltiplo, consciente/inconsciente, natureza/história, corpo/alma. Compõese de quinze platôs; conceito tomado de empréstimo a Gregory Bateson (antropólogo e sociólogo que trabalha conceitos de ecologia da mente e é um dos fundadores, ao lado de Wiener, do conceito de cibernética). O platô é definido por Bateson ${ }^{5}$ (apud DELEUZE E GUATTARI, 1995, p. 47) como "uma região contínua de intensidades, vibrando sobre ela mesma, e que se desenvolve evitando toda orientação sobre um ponto culminante ou em direção a uma finalidade exterior". Um platô está sempre no meio, nunca no início ou no fim.

\footnotetext{
${ }^{5}$ BATESON. Vers une écologie de l'esprit. Paris: Seuil, 1977. t. 1.
}

InCID: R. Ci. Inf. e Doc., Ribeirão Preto, v. 1, n. 2, p. 21-36, jul./dez. 2010. 
Um rizoma é feito de platôs. Rejeita, portanto, as dicotomias e a hierarquia como modelos de organização.

\begin{abstract}
Um rizoma não começa nem conclui, ele se encontra sempre no meio, entre as coisas, inter-ser, intermezzo. A árvore é filiação, mas o rizoma é aliança, unicamente aliança. A árvore impõe o verbo "ser", mas o rizoma tem como tecido a conjunção "e... e... e..." Há nesta conjunção força suficiente para sacudir e desenraizar o verbo ser (DELEUZE; GUATTARI, 1995, p. 35).
\end{abstract}

O volume um de Mil Platôs traz uma espécie de orientação, de guia para a leitura do texto. Nesta advertência apresenta e já desenvolve o conceito de rizoma, motivo pelo qual é preciso compreender um pouco melhor esta concepção de leitura. Os autores avisam que a obra não deve ser lida seguindo-se uma abordagem tradicional. Deve, sim, ser entendida já no modelo rizomático. Deleuze ainda se refere, em obra, à ideia do que se pode chamar, a sua revelia, uma nova estética da recepção de leitura, numa passagem em que busca dessacralizar o livro:

[...] tratar um livro como se escuta um disco, como se olha um filme ou um programa de televisão, como se é tocado por uma canção: todo tratamento do livro que exigisse um respeito especial, uma atenção de outra espécie, vem de uma outra era e condena definitivamente o livro. Não há nenhuma questão de dificuldade nem de compreensão: os conceitos são exatamente como sons, cores ou imagens, são intensidades que convêm a você ou não, que passam ou não passam. Pop filosofia. Nada há a compreender, nada a interpretar (DELEUZE; PARNET, 1998, p. 10).

É preciso confessar, contudo, que nem sempre se experimenta tal fruição na leitura de Deleuze. Se for possível comparar sua obra com um disco este certamente não será um disco pop banal, como faz transparecer a citação acima.

Os modelos mais tradicionais de escritura e leitura são pautados na concepção linear de início, meio e fim, ou, para preservar a terminologia dos estudos de gêneros textuais: introdução, desenvolvimento e conclusão. Nesta ordem canônica só se pode, teoricamente, avançar a partir da conclusão. A conclusão encerra, por assim dizer, um texto e abre novas possibilidades.

Para Deleuze e Guattari o livro interessa apenas enquanto agenciamento em conexões com outros agenciamentos, "em relação com outros corpos sem órgãos".

Não se perguntará nunca o que um livro quer dizer, significado ou significante, não se buscará nada compreender num livro, perguntar-se-á com o que ele funciona, em conexão com o que ele faz ou não passar intensidades, em que multiplicidades ele se introduz e metamorfoseia a sua, com que corpos sem órgãos ele faz convergir o seu. Um livro existe apenas pelo fora e no fora (DELEUZE; GUATTARI, 1995, p. 11).

Deleuze e Guattari propõem para a leitura de Mil Platôs a mesma estratégia de pensamento que pretendem apresentar e desenvolver ao longo da obra para a leitura do 
mundo: a abordagem rizomática. Nessa abordagem rompe-se com a linearidade aparente. Compreendendo que o livro não possui capítulos que se sucedem, mas platôs, ou zonas que possibilitam novas conexões, entendem os autores que o leitor pode, livremente, traçar seu percurso de leitura, saltar de um platô a outro, construindo seu rizoma conforme a orientação de sua própria concepção. Os platôs não possuem necessariamente início ou fim. Pode-se entrar ou sair deles por qualquer ponto; mas formam, ainda assim, uma rede, um rizoma, uma multiplicidade.

Por exemplo, uma vez que um livro é feito de capítulos, ele possui seus pontos culminantes, seus pontos de conclusão. Contrariamente, o que acontece a um livro feito de "platôs" que se comunicam uns com os outros através de microfendas, como num cérebro? Chamamos "platô" toda multiplicidade conectável com outras hastes subterrâneas superficiais de maneira a formar e estender um rizoma. Escrevemos este livro como um rizoma. Compusemo-lo com platôs. Demos a ele uma forma circular, mas isto foi feito para rir. Cada manhã levantávamos e cada um de nós se perguntava que platôs ele ia pegar, escrevendo cinco linhas aqui, dez linhas alhures. Tivemos experiências alucinatórias, vimos linhas, como fileiras de formiguinhas, abandonar um platô para ir a um outro (DELEUZE; GUATTARI, 1995, p. 32).

É impossível não estabelecer, neste ponto, paralelos com a concepção de hipertexto e com a geografia da internet, com o que há de concepção romântica na ideia abraçada por muitos estudiosos nos anos 1990 (o boom da internet) sobre a liberdade anárquica da rede. Mil platôs é de 1980, quando a internet ainda principiava, sem a visibilidade da web, que ganharia desenvolvimento apenas na década seguinte Não há, portanto, na obra, qualquer referência explícita à ampla teia mundial. Sua configuração, entretanto, convida ao paralelo que se estabelece com base nos princípios do rizoma e nas características da internet, a partir da leitura de Hamman (1996), apresentado no Quadro 1. O agrupamento dos princípios, que serão mais detalhados na seção 5, segue a proposta de Deleuze e Guattari (1995). 
QUADRO 1 - Comparação entre rizoma e internet

\begin{tabular}{|c|c|}
\hline \multicolumn{2}{|r|}{ 1ㅇ e 2o princípios - Conexão e heterogeneidade } \\
\hline RIZOMA & Qualquer ponto do rizoma pode ser conectado a qualquer outro ponto. \\
\hline INTERNET & A descentralização como princípio fundamental no surgimento da internet. \\
\hline & $\begin{array}{l}\text { O envio de pacotes de informação de um computador para qualquer outro, em rotas pré- } \\
\text { estabelecidas ou não. }\end{array}$ \\
\hline & Qualquer computador, preparado para rede, pode conectar-se. \\
\hline \multicolumn{2}{|r|}{ 3o princípio - Multiplicidade } \\
\hline RIZOMA & $\begin{array}{l}\text { Contraposição às relações dicotômicas e hierárquicas; não existem pontos ou posições, apenas } \\
\text { linhas em um rizoma. }\end{array}$ \\
\hline INTERNET & $\begin{array}{l}\text { À primeira vista, este princípio parece colocar em dúvida a utilização da internet como um exemplo } \\
\text { de rizoma, pois o internauta vai de um ponto a outro, usando os endereços eletrônicos para } \\
\text { encontrar e ler os sites. É preciso considerar, entretanto, que não se movimenta fisicamente entre } \\
\text { os pontos, em vez disso permanece no mesmo local físico em todo o tempo de navegação. Não há } \\
\text { pontos para ir que existam além do estado de alucinação consensual que é o ciberespaço, } \\
\text { conforme a descrição de Gibson (1991). }\end{array}$ \\
\hline
\end{tabular}

4o princípio - Ruptura a-significante

\begin{aligned} & \hline RIZOMA $\begin{array}{l}\text { Um rizoma não tem começo ou fim, pode ser rompido em qualquer lugar, pois retoma segundo } \\ \text { uma ou outra de suas linhas e segundo outras linhas. } \\ \text { A internet foi projetada para resistir a um holocausto nuclear, seus protocolos permitem que os } \\ \text { computadores que a compõem possam redirecionar os pacotes de informação em pontos de } \\ \text { INTERflito. }\end{array} \\ &$\hline RIZOMA e 60 princípios - Cartografia e decalcomania \\ & $\begin{array}{l}\text { O rizoma não é objeto de reprodução, porque não tem centro, hierarquia e corte significante, } \\ \text { então, suas ligações ilustram um mapa, e como tal possui várias entradas. }\end{array} \\ &$ INTERNET $\begin{array}{l}\text { Existem muitos links entre computadores na internet, do mesmo modo, existem muitas entradas, já } \\ \text { quescolher qualquer site como entrada. Assim, o internauta cria mapas ligando páginas e } \\ \text { movendo-se como um nômade que está navegando. }\end{array}\end{aligned}$

\section{A multiplicidade e a árvore}

Um dos conceitos mais caros a Deleuze e Guattari em todo Mil Platôs é o da multiplicidade. Na concepção sumarizadora de Abreu Filho (DELEUZE; GUATTARI, 1998, p. 143):

A teoria da multiplicidade efetua uma interpretação do real que conjuga uma construção ontológica e uma leitura do mundo e da sociedade que surpreende com uma nova distribuição dos seres e das coisas: não admite unidade natural, uma vez que não se apóia em nenhuma necessidade e não visa a nenhum prazer; não reconhece a falta, uma vez que não se constitui em referência a uma unidade ausente (recusando, pois, a noção de desejo como falta); e não aceita nenhuma transcendência - seja na origem, como idéia ou modelo, seja no destino, como sentido historicamente desenvolvido. A perspectiva da imanência e o conceito de multiplicidade fazem do pensamento uma atividade ética - sem modelos e finalidades transcendentes - avessa a qualquer conforto moral ou orientação histórica (grifos nossos).

InCID: R. Ci. Inf. e Doc., Ribeirão Preto, v. 1, n. 2, p. 21-36, jul./dez. 2010. 
A multiplicidade pode ser contraposta à concepção de unicidade disseminada pelo uso da estrutura arborescente como metáfora para a representação do conhecimento, utilizada, pelo menos, desde a Idade Média, podendo-se citar a célebre Árvore de Porfírio (cuja base é aristotélica) e todos os seus desdobramentos como exemplos.

A longa permanência desse modelo de representação ocorre em função de dois aspectos compreensíveis (BURKE, 2003): a) a abordagem dicotômica simplificada revelada na oposição entre os elementos pela presença/ausência de determinada propriedade e b) a naturalização do convencional, pela apresentação da cultura como se fosse natureza. Apenas no século XVI aparece a noção de sistema, como representação mais complexa.

Para Deleuze e Guattari (1995, p. 29), toda lógica da árvore é uma lógica do decalque e da reprodução. No volume 4 de Mil Platôs, Deleuze e Guattari (1997) criticam mais duramente a metáfora da árvore e seu devir condicionante. Compreendem o devir como "um movimento pelo qual a linha libera-se do ponto, e torna os pontos indiscerníveis: rizoma, o oposto da arborescência, livrar-se (sic) da arborescência”.

A lógica da arborescência, e a dualidade que a constitui, aplicada às linguagens documentárias, numa visão clássica, dá ideia de que há desdobramentos a partir dos dipolos ${ }^{6}$ de ligação. Citando textualmente Deleuze e Guattari (1995, p. 25):

\begin{abstract}
A árvore ou a raiz inspiram uma triste imagem do pensamento que não pára de imitar o múltiplo a partir de uma unidade superior, de centro ou de segmento. Com efeito, se se considera o conjunto galhos-raízes, o tronco desempenha o papel de segmento oposto para um dos subconjuntos percorridos de baixo para cima: um tal segmento será um "dipolo de ligação", diferentemente dos "dipolos-unidades" que formam os raios que emana de um único centro.
\end{abstract}

Isso está refletido na análise que Lara (1993) realizou de algumas linguagens documentárias (tesauros e classificações decimais). A partir da análise de alguns casos, concluiu que o uso de mais de uma característica de divisão para a construção de hierarquias é predominante na CDD e na CDU, o que implica a coordenação de termos que não possuem a mesma natureza. Este problema, aliás, já havia sido detectado por Coyaud ${ }^{7}$ (apud LARA, 1993). A autora observou a mesma estruturação hierárquica dos domínios na análise dos tesauros, com predomínio das relações gênero-espécie e todo-parte.

\footnotetext{
${ }^{6}$ A interação química dipolo-dipolo ou dipolo permanente refere-se, basicamente, à força de atração que ocorre entre duas moléculas polares que se ligam por seus respectivos pólos, ou seja o pólo positivo de uma molécula liga-se ao pólo negativo de outra.

${ }^{7}$ COYAUD, M. Introduction a I'êtude des langages documentaires. Paris: C. Klincksíeck, 1966.
}

InCID: R. Ci. Inf. e Doc., Ribeirão Preto, v. 1, n. 2, p. 21-36, jul./dez. 2010. 
Há aqui um paradoxo. Credita-se a Aristóteles a supremacia da hierarquia ainda presente nos modelos de organização do conhecimento em detrimento de modelos contemporâneos alternativos. $\mathrm{O}$ uso de mais de uma característica de divisão e a presença de relações lógicas e associativas demonstram, entretanto, mais influência da base empírica do registro (LARA, 1993) do que da lógica aristotélica.

\section{Revendo as estruturas}

O conceito de multiplicidade é, sob certos aspectos, contraposto ao conceito de estrutura. A estrutura, na compreensão deleuzeana, impede o crescimento quando engessa as possibilidades num feixe pré-programado de possibilidades. Dessa forma "toda vez que uma multiplicidade se encontra presa numa estrutura, seu crescimento é compensado por uma redução das leis de combinação" (DELEUZE; GUATTARI, 1995, p. 13).

Apresentam-se, com o fim de elucidação, as principais características aproximativas dos rizomas concentradas em alguns princípios: $1^{\circ}$ e $2^{\circ}$ - Princípios de conexão e de heterogeneidade; $3^{\circ}$ - Princípio de multiplicidade; $4^{\circ}$ - Princípio de ruptura a-significante e $5^{\circ}$ e $6^{\circ}$ - Princípio de cartografia e de decalcomania. Cada um deles é detalhado nos itens subsequentes.

\section{$1^{\circ}$ e $2^{\circ}$ - Princípios de conexão e de heterogeneidade}

Como garantia de que todas as possibilidades estejam abertas, "qualquer ponto de um rizoma pode ser conectado a qualquer outro e deve sê-lo". Este princípio é contrário, então, a qualquer forma de hierarquia ou de estrutura nos moldes como são mais conhecidas e utilizadas nos processos de representação do conhecimento. Retomando as críticas ao estruturalismo, Deleuze e Guattari (1995, p. 14-15) usam a gramaticalidade de Chomsky para evidenciar seu poder disciplinador ou homogeneizador: "o símbolo categorial S que domina todas as frases, é antes de tudo um marcador de poder antes de ser um marcador sintático [...]. Você constituirá frases gramaticalmente corretas, você dividirá cada enunciado em sintagma nominal e sintagma verbal (primeira dicotomia)" e assim por diante. Contrariamente à estrutura, que depende do relacionamento biunívoco entre os pontos para o estabelecimento 
de uma identidade relacional, os rizomas traçam linhas incertas, pontos de fuga e de desterritorialização.

Este desenho rizomático está presente hoje nas representações que se constroem da internet e sua hipermidialidade. A riqueza da internet, enquanto rede de comunicação planetária que é, está na abundância; na possibilidade que esta tecnologia cria para que pessoas de variadas nacionalidades, de variados idiomas ou culturas, lançando mão de variadas mídias, possam interagir.

Neste ponto coloca-se, aliás, um dos principais problemas atuais da ciência da informação: como garantir a organização do conhecimento e o acesso à informação registrada em suportes tão diferentes, mutantes, fluidos? Há condições suficientes para interação (entre pessoas), mas ainda insuficientes para a interatividade (pessoas e máquinas ou máquinas entre si) quando se trata do fluxo da informação documentária. Na perspectiva do ciberespaço, a subjetividade (quer seja do indivíduo mesmo ou da instituição) nas representações hierarquizadas, assumiria a perspectiva do uno e condenaria os sistemas de informação ao isolamento ou à formação de pequenos agrupamentos que só poderiam dialogar entre si.

\section{$3^{\circ}$ - Princípio da multiplicidade}

É importante enfatizar que o conceito de multiplicidade não se opõe, quer contrária ou contraditoriamente, ao conceito de unidade, pois dessa forma estabelecer-se-ia simplesmente uma continuidade das dicotomias. Deleuze e Guattari (1995, p. 15) preferem tratar o múltiplo como substantivo; tratado como multiplicidade "ele não tem mais nenhuma relação com o uno como sujeito ou como objeto, como realidade natural ou espiritual, como imagem e mundo". A divisão estanque sujeito e objeto (outra dicotomia), tão cara ao positivismo, estaria superada.

Aos elos que são estabelecidos como garantia de multiplicidades, ao "crescimento das dimensões, numa multiplicidade que muda necessariamente de natureza à medida que ela aumenta suas conexões”, Deleuze e Guattari (1995, p. 16) denominam agenciamento.

Os pensadores sabem, no entanto, que não se apaga simplesmente o sujeito com sua inserção numa teia de agenciamentos. A noção de unidade continua aparecendo "quando se produz numa multiplicidade uma tomada de poder pelo significante ou um processo 
correspondente de subjetivação" (DELEUZE; GUATTARI, 1995, p. 16). No ambiente atual dos sistemas de informação, marcado por virtualidades a questão do sujeito-autor tem sido amplamente discutida, como já fora apontado por Foucault e explorado por Coelho Netto (1994). A partir da indagação de Foucault, 'Qu'est-ce qu'un auteur?', Coelho Netto apresenta questões interessantes e (ainda) atuais sobre o que o filósofo, pensava, em 1959, a respeito desta entidade. Uma delas é negação do autor por Foucault ${ }^{7}$ (apud COELHO NETTO, 1994), para quem existe apenas uma função-autor, responsável pela geração de um texto, "instauradores de discursos", "formadores de discursividade", o indivíduo funciona como catalisador desse processo.

Nos atuais modelos de produção e uso de informação, possibilitados pela complexa conjunção de tecnologias de informação e de comunicação que se convencionou chamar simples e resumidamente de internet, torna-se cada vez mais comum a produção coletiva de conhecimentos.

\title{
$4^{0}$ - Princípio de ruptura a-significante
}

Uma estrutura, na definição clássica de Piaget (1979, p. 6)

\begin{abstract}
é um sistema de transformações que comporta leis enquanto sistema (por oposição às propriedades dos elementos) e que se conserva ou se enriquece pelo próprio jogo de suas transformações, sem que estas conduzam para fora de suas fronteiras ou façam apelo a elementos exteriores. Em resumo, uma estrutura compreende os caracteres de totalidade, de transformações e de auto-regulação.
\end{abstract}

Na visão pós-estruturalista de Deleuze e Guattari (1995, p. 17) é preciso investir contra a rigidez da estrutura. No modelo estruturalista auto-regulador qualquer ruptura tornase necessariamente significante e fere todo o sistema, podendo, inclusive, atravessá-lo. Um rizoma, por sua vez, esclarecem os autores "pode ser rompido em um lugar qualquer, pois retoma segundo uma ou outra de suas linhas e segundo outras linhas". Em outra passagem (p. 13) sustentam: "Toda vez que uma multiplicidade se encontra presa numa estrutura, seu crescimento é compensado por uma redução das leis de combinação".

Há sempre o incômodo na denominação de pós-estruturalista para a filosofia de Deleuze, pois, como salientam Mostafa e Nova Cruz (2009, p. 10), inserir o pensamento de Deleuze numa linearidade, "somente dá lugar à reincidência dos mesmos conceitos de tempo que a história e a historiografia tradicionais têm utilizado para refletir sobre fatos passados e comunicá-los, sem colocá-los no plano de imanência do vivido, do devir e do acontecimento".

InCID: R. Ci. Inf. e Doc., Ribeirão Preto, v. 1, n. 2, p. 21-36, jul./dez. 2010. 


\section{$5^{\circ}$ e $6^{\circ}$ - Princípio de cartografia e de decalcomania}

"Um rizoma não pode ser justificado por nenhum modelo estrutural ou gerativo. Ele é estranho a qualquer idéia de eixo genético ou de estrutura profunda" (DELEUZE; GUATTARI, 1995, p. 20). Esta rejeição deve-se à compreensão de que o eixo ou a estrutura "são antes de tudo princípios de decalque, reprodutíveis ao infinito". A própria ideia de eixo, como linha imaginária ou real que determina o centro de um corpo é estranha à concepção do rizoma. A ideia de eixo aqui remete novamente à lógica da árvore, criticada vigorosamente pelos pensadores em estudo: "toda lógica da árvore é uma lógica do decalque e da reprodução" (DELEUZE; GUATTARI, 1995, p. 21). A árvore, prosseguem, "articula e hierarquiza os decalques", reproduz a si mesma quando pensa reproduzir o outro.

O relativo insucesso de grandes projetos nos campos da biblioteconomia e da documentação, como a universalização da classificação ou a criação de um centro mundial de documentação, pode ser tributado, em parte, a sua condição inerente de reprodução, de decalque a partir de um eixo principal, representado pela ideologia manifesta em adjetivos como universal e mundial, que tendem a ignorar a multiplicidade. 


\section{Considerações finais}

Deleuze foi saudado por Foucault ${ }^{8}$ (apud DELEUZE, 1992, p. 111) como instaurador de um novo pensamento, como um marco na filosofia:

Produziu-se uma fulguração, que levará o nome de Deleuze. Um novo pensamento é possível, de novo o pensamento é possível. Ele está aí, nos textos de Deleuze, saltitante, dançante, diante de nós, entre nós... Um dia talvez o século será deleuzeano.

Fazendo coro com Foucault, guardadas as devidas proporções, acredita-se que as ideias colhidas do pensamento de Deleuze indicadas neste trabalho possam ser aprofundadas e se tornar contributivas para uma releitura dos modelos de representação e, consequentemente, dos modelos de recuperação da informação no âmbito da ciência da informação. São forças quase contraditórias: de um lado a rejeição da ideia de representação em favor da multiplicidade e de seus agenciamentos, de outro a representação como fundamento epistemológico. Até que ponto, pode-se perguntar, a lógica do decalque interfere positiva ou negativamente nos processos usuais de representação da informação? Que contribuições as ontologias oferecem neste contexto?

A virtualização (desmaterialização) dos documentos e sua desterritorialização trouxeram novos desafios para o subcampo da organização da informação e seu conjunto de técnicas, mais apropriado ao tratamento de documentos estabelecidos numa relação tempoespaço. O pensamento rizomático deleuzeano permite instaurar um novo olhar para as redes de informação, para uma nova pragmática das ações de informação, sem a necessidade de adoção de um modelo regulado por um eixo específico, o que é, aliás, condição necessária para a organização e recuperação da informação no ciberespaço.

Algumas questões impõem-se neste novo cenário: qual a melhor opção para disponibilização do objeto de informação eletrônico se o conceito de estoque tornou-se instável, se não há mais árvores que possam abrigá-los? Ainda são necessárias a descrição e a representação do documento (é preciso lembrar que documento e seus metadados não estão fisicamente separados) ou eles mesmos se bastam? Se as técnicas de organização da informação tradicionais referem-se fortemente à informação tridimensional, como adaptar-se à ausência de fronteiras? É possível repensar a construção de informações documentárias para 
encontrar algo semelhante ao mundo Google ${ }^{\mathrm{TM}}$ no tratamento da informação sintática e ao mesmo tempo rico em possibilidades semânticas como o rizoma deleuzeano? Provocações...

\section{Referências}

BURKE, Peter. Uma história social do conhecimento: de Gutenberg a Diderot. Rio de Janeiro: Jorge Zahar, 2003.

CABRÉ, Maria Teresa; MOREL, Jordi; TEBÉ, Carles. Las relaciones conceptuales de tipo causal: un caso práctico. In: SIMPOSIO IBEROAMERICANO DE TERMINOLOGÍA, 5., 1996, Cidade do México. Anais eletrônicos... Cidade do México: RITerm, 1996. Disponível em: <http://www.riterm.net/actes/5simposio/cabre6.htm> Acesso em: 14 jul. 2008.

COELHO NETTO, José Teixeira. O autor, ainda. Imagens, n. 3, p. 69-73, dez. 1994.

DELEUZE, Gilles. Conversações: 1972-1990. Rio de Janeiro: 34, 1992.

DELEUZE, Gilles; GUATTARI, Felix. Mil platôs: capitalismo e esquizofrenia: vol. 1. Rio de Janeiro: 34, 1995. . Rio de Janeiro: 34, 1997. v. 4.

Mil platôs: capitalismo e esquizofrenia. Rio de Janeiro: 34, 1995-1997. 715 p.

Resenha de: ABREU FILHO, Ovídio. Mana, v. 4, n. 2, p. 143-146, 1998.

DELEUZE, Gilles; PARNET, Claire. Diálogos. São Paulo: Escuta, 1998.

GIBSON, William. Neuromancer. São Paulo: Aleph, 1991.

HAMMAN, Robin B. Rhizome@internet: using the internet as an example of Deleuze and Guattari's "rhizome". 1996. Disponível em:

$<$ http://www.swinburne.infoxchange.net.au/media/halm316/gallery/david/pg11b.htm $>$. Acesso em: 01 mar. 2010.

INTERNATIONAL STANDARDIZATION FOR ORGANIZATION. ISO 704: terminology work - principles and methods. Geneva, 2000.

LARA, Marilda L. G. Representação documentária: em jogo a significação. 1993. 133 f. Dissertação (Mestrado em Ciências da Comunicação) - Universidade de São Paulo, Escola de Comunicações e Artes, Departamento de Biblioteconomia e Documentação, 1993.

LECHTE, John. 50 pensadores contemporâneos essenciais: do Estruturalismo à PósModernidade. Rio de Janeiro: Difel, 2002.

MOSTAFA, Solange P.; NOVA CRUZ, Denise V. Para ler a filosofia de Gilles Deleuze e Félix Guattari. Campinas: Alínea, 2009. 
PIAGET, Jean. O estruturalismo. 3. ed. São Paulo: Difel, 1979.

ROUDINESCO, Elisabeth. Giles Deleuze: variações antiedipianas. In: Filósofos na

tormenta: Canguilhem, Sartre, Foucault, Althusser, Deleuze e Derrida. Rio de Janeiro: Zahar, 2007. p. 204-217.

Artigo submetido em 08 nov. 2010

Artigo aceito em 04 dez. 2010 